\title{
Comments on Cristinel Munteanu’s contribution
}

Munteanu presents Hasdeu, who early understood that linguistics is not a natural science "as botany, for example”. It is almost comical that Hasdeu manages to choose as example the only science he should not have chosen. Linné (Linnaeus) in his botany is not interested in evolution, law, cause, effect, prediction and explanation. Linné is the greatest taxonomist of all times and all sciences. Too deficient a taxonomy has generally had a negative effect on linguistics even if historical linguists and the so-called generative linguists have clearly been particularly deficient in this regard. What is more important for good description than thorough classification based on defining well what one classifies? I do not believe there is any orientation in linguistics or any linguist who has presented a perfectly detailed and coherent classification of language facts. Less Darwin and natural sciences in general and more Linné would have been of great advantage to linguistics. Munteanu provides interesting viewpoints on the tripartite division of sciences which has been well explained (=clarified) by Coseriu and others: mathematical, natural and cultural sciences. I believe that both young linguistics students and established linguists should have a clear idea about these things but a great many of them probably do not. Like textbooks in linguistics they would say that linguistics is the science (or study) of language but they would not be able to go much further. Would they know what kind of science linguistics is? And if they knew that it is a cultural or humanistic science, would they then be able to discuss similarities and differences between this kind of science and mathematical and natural sciences? I have recently given much weight to the cultural aspect of language when trying to understand major language changes. In language and in other branches of culture, which I mention for comparison, an innovation comes from an individual and spreads to others. If one wants to understand why this happens, there is no causal explanation. Like the innovators the individuals involved find that the innovation is interesting, beautiful, pleasing, attractive or such like. I also believe that there is an element of variatio delectat when a change is made, the change itself is attractive. For these and other facts which result in changes I have suggested the term prompt. It has some similarity with cause without being one. Minor changes can often be found to have something like a cause. I would call it a strong causal element. In phonetics a vowel in some position in the word may fall out and the result may be a new combination of consonants which is more or less impossible to pronounce. This causes a further change in pronunciation. In the vocabulary a new thing may need a new word. Italian immigrants have introduced both pizza and the word pizza to many societies. The vocabulary has changed somewhat by being enlarged. Such causes are, however, incomplete. It is only the change that is given. The form of the change is not given because there is more than one possible way of solving the problem when one introduces a new pronunciation or a new expression. These are the views which I believe are the basic ones in relation to the major and minor changes. I have explained them in more detail in Fundamentals of Diachronic Linguistics. München: Lincom Europa 2012. 